\title{
Discussion and Research on Electronic Resources Navigation System
}

\author{
Yuying Liu \\ Shengyang Aerospace University Libarary \\ Shengyang Aerospace University \\ Shengyang China \\ liuyuying@sau.edu.cn
}

Keywords: University library; Electronic resources navigation system; Free electronic resources navigation; Mobile retrieval terminal

\begin{abstract}
As the increasing status of electronic resources in university library, and the increasing introduction of electronic resources in university library, it is particularly important to use electronic resource navigation system in university library. This paper discuss and research on the electronic resources navigation system of the university library. This article will explore the electronic resources navigation system application in university library from these aspects: the integration of electronic resources in university libraries; the resource utilization of Internet free electronic resources; demand for mobile retrieval terminal; profit model etc.
\end{abstract}

\section{Introduction}

With the rapid development of higher education, the library plays an increasingly important role in the teaching and scientific research. Electronic data resource share is more and more high proportion in the university library collection. An ordinary commercial databases may be more than a small university library collection on the amount of information. As the national investment in university library, each university library has introduced a variety of electronic database resources, these electronic resources are based on various periodicals databases, and also includes other data types such as books, video and audio, etc. Periodical resources can reflect the latest developments in a specific subject in real time, and it is the resource type of the highest utilization in the library. With the rapid development of information technology, electronic journal resources with the advantage of its powerful retrieval function, update aging fast, gradually became an important resource of the library, and become the main way to get professional literature information for the teachers and students in colleges universities and scientific research workers, also play asignificant role in teaching and research. All databases root in different publishers and information providers, which collection of journals and retrieval platform also vary, and its content preferences, retrieval methods and habits are different. When teachers and researchers want to find a journal, they need to spent a lot of time and energy in the familiar each kind of database operations, which greatly reduces retrieval efficiency, seriously affecting the utilization of electronic resources. If you want to effectively use the electronic data resources, the the librarians should effectively comb electronic resources of the library, and collect resources is persed in the different database, different access mode of electronic resources together. They need to integrate existing purchase of all of its resources, and to establish multi-functional 
navigation system with browsing, query and others. Then, it will provide the reader with a more convenient and quick retrieval way.

\section{Integration of Library Electronic Resources}

Each university library introduced a variety of electronic data resources, such as: Shengyang Aerospace University existing 17 foreign database, 15 Chinese databases; JiLin University existing 79 foreign database, 37 Chinese databases; Tsinghua University existing 90 foreign database, 54Chinese databases. Thus, it will make people confused with the increasing database types and database variety, with dazzling. So it is also increasingly urgent demand to establish the electronic resource navigation system.

In fact, each university library has established their own electronic resources navigation system. When the database type is relatively small, this simple navigation system can also meet the needs of readers. But, more than 10 species or dozens of species of the database type, simple quoting database directory feature has moved from the traditional simple page transitions to the Ribbon UI interface. So if there is no professional custom navigation system , the reader will be very puzzled, especially the student who is new to the science and technology literature retrieval.

With the increasing of database types, the navigation system is based on the classification of subjects, which is the mainstream classification method in the current university electronic resources navigation system. The retrieval system manages the requirement of database by classifies the subjects, and also classified navigation according to the readers' needs and preferences, retrieval method, the data type, resource type and so on. For example, Electronic journal navigation system include the retrieval, browse, system maintenance three function modules and so on. The journal retrievals including journal name, title, abstract and keywords for literature retrieval; classification browsing lets users according to the subject, journal name in literature retrieval; the management and maintenance module can realize system running and maintenance and database update operations. Specific function structure diagram as shown in Fig. 1.

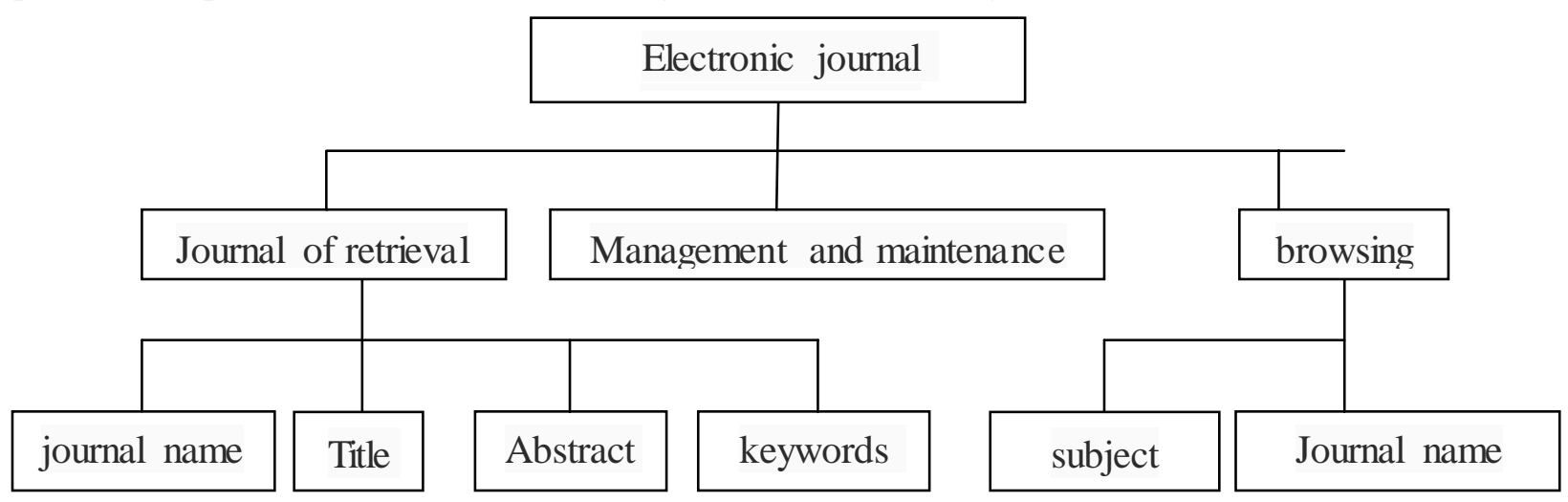

Fig. 1 Specific function structure diagram

\section{Establish Free Electronic Resources Navigation in a Network}

In addition to introduce electronic data resources of university library, the Internet also has a lot of free electronic resources, for example: Google academic, baidu library, wikipedia, all kinds of academic BBS and so on. These free resources is the beneficial supplement of electronic resources in 
university library, and effective use of Internet resources will also be one of the important function of electronic resources navigation system. According to the questionnaire of a university, in terms of percentage, it is about $46.4 \%$ resources that graduate student get science and technology literature resources from the Internet.

University library electronic resources navigation system should not only satisfied with the introduction of database management, it more should develop the network free resources navigation function in the deep function. It should be classified in subject, data types, resource types of free online resources, then it will facilitate readers to query, download and read. For the scattered data online, various universities library should collect the free online data establish a local mirror data repository, in order to satisfy the demands of the reader's retrieval.

\section{Mobile Retrieval Terminal}

Wireless network coverage has gone deep into every corner of our lives and works, full wireless network coverage of universities have nothing new. With the popularity of mobile Internet, the demand of mobile retrieval terminal is important of the library electronic resources highlights. What the PC can do online through the Internet, it will soon realize in the mobile terminal. In the primary stage of development for mobile terminals, e-book is a kind of important products. Thus, the realization of library electronic resources on retrieval, search and download of mobile terminals, may simply be the simple combination of mobile Internet technology and e-book technology.

Nowadays, many universities have set up their own mobile library application for smart phones and tablet computer users.( Fig. 2 shows Shengyang Aerospace University library mobile library application interface)

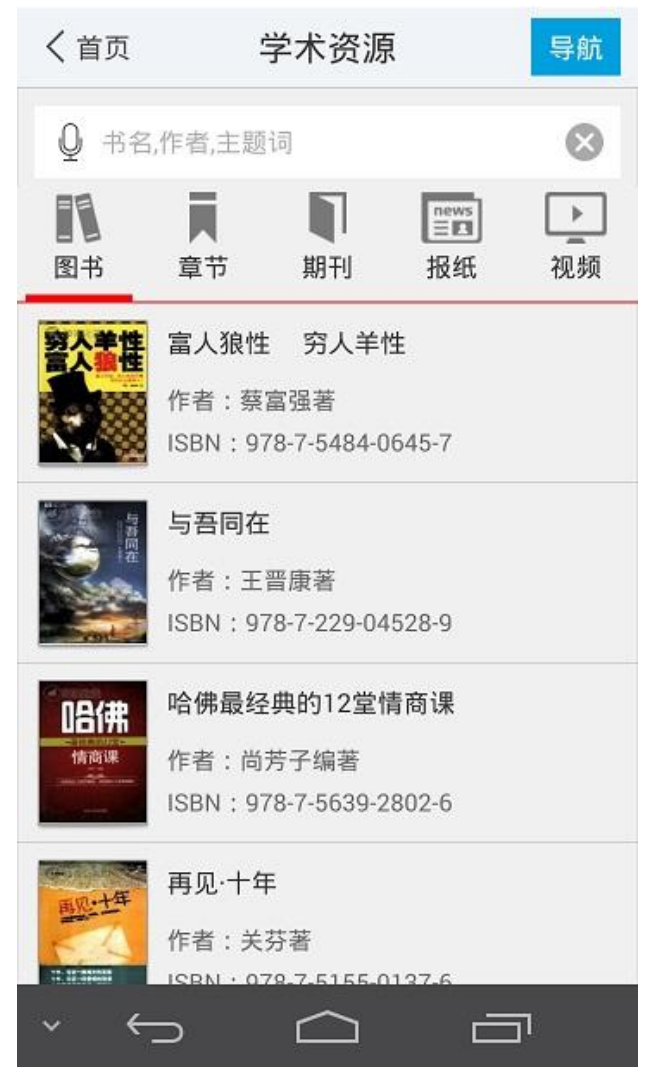

Fig. 2 mobile library application interface 
Mobile Library provide a more convenient mobile service for teachers and students in universities. At present, the application of mobile library terminal has search, book reviews, consult the library functions and full-text retrieval of data, download, and mobile reading. Readers can login by student ID number, and it will provide the reader with library information query, renew, appointments, and other functions, at the same time they can view the latest news in university library, dynamic resources and services to help and guide through the mobile library client.

With the continuous development of mobile wireless network, the electronic resources navigation system will be growing in the mobile terminal simultaneously, and they have the same function with a PC, to provide readers with a more convenient and efficient retrieval approach.

\section{Create the Profit Pattern of the Internet Age}

Electronic resources navigation system is the potential of the information age, it will bring huge economic benefits in the service for the readers, and even can bring the library ind ustry revolution. The United States Google Corporation which is the overlord in the Internet age , established the retrieval system for the library retrieval system on the technology .

Electronic resources navigation system is the target customer of all kinds of readers, especially scientific research workers. The characteristics of this group is for rapid, accurate and efficient to get knowledge, rather than simple, mechanical browsing the web. The electronic resources navigation products focus on the user application of convenient and quick, accurate and efficient. When the electronic resources navigation system is established a stable user group, the user can obtain continuous, high-quality services. Then, this system will be a valuable Internet quality products. Knowledge is power. Librarians are the group of management knowledge, with the new technologies of the information age, the electronic resources navigation will bound to obtain tremendous benefits when they server the readers.

\section{The Design Requirements of the Electronic Resources Navigation System}

The Completeness And Accuracy of Library electronic resources. The information of the electronic resources in the collection must be recorded accurately to the navigation system, so that the readers can navigate the navigation system through the uniform retrieval service interface. In order to let readers have a more comprehensive understanding of the electronic resources, the system need to provide the following some basic information: the name of the resource, subject classification, access address; at the same time also need to illustrate the detailed information of all kinds of resources. For example, we can establish two data table of the navigation system : basic information and detailed information.

Provide a unified, convenient retrieval entrance. When the user retrieve the navigation system, the navigation entry address which access a variety of electronic resources in the navigation system will be dynamically extracted from the database table. And the navigation page entry address will be created through the JSP program, then the user can click on the link to access the page directly.

Improve readability of the system. While integrating the database, we should strengthen the integrity of the system, and also provide a more convenient reading system. We will form a complete system that is convenient retrieval and reading, so that the navigation system function will be more perfect, and do not need to add some extra cumbersome reading procedures. 
Provide browsing Function of electronic resources. The navigation system provide a certain way of browsing resources, so that readers so that readers can find accord with certain conditions of electronic resources in the navigation system when they do not understand the system ,also they can find unknown resources in the range of cost less.

Tracking the changes of electronic resources information. Establish an efficient resource information navigation system to track online resources changes, we will establish an online navigation system that can possible update information and maintain effective management. We can prepare an effective tool to update the directory and find the resources recommended, or some search engine, electronic resources URLs integrators, and accelerate the creation of an effective system of links, updated data to provide timely service.

Improve Data Quality and Quantity of the Resource Record. Whether it is online or print edition of the journal and other products, they will be established electronic version and standard format in publication, and cooperated with data publishers in proper form. Then the programmers will connect the retrieval results from indexing database of navigation system with the corresponding journal full text number database, and to establish a multifunctional network technology platform. Through to support the distribution of electronic periodicals information system interoperability and seamless exchange and sharing of information resources, we will build a logic of the integrated information service mechanism, also build a three-dimensional network, interconnected system of knowledge resources according by the logical relationship of electronic journal resource organization.

\section{Conclusions}

The electronic resources navigation system is an important content of the library network resources construction, and the electronic resources in the library service in the proportion is more and more big, status is also more and more important. Application characteristics and technology characteristics of the electronic resources navigation system which determines to on the one hand serve the readers of the library, on the other hand to keep up with the development of new technology. Same as other more library services, the electronic resources navigation system should use the scientific management and advanced technology to perfect the function of the system, and then they can ensure that the reader can convenient, quickly and accurately find the required documents. As countries and universities increasing importance to library's work, electronic navigation systems will no doubt play an important role in life.

\section{References}

[1]Fang Baohua. Problems and Countermeasures of the Electronic Journal Navigation System in University Library [J]. University Library Journal,2006,24(1):74-78.

[2]Ma Jianling. Discussed in Electronic Journal of Organizational Issues [J]. Modern intelligence, 2005,(2): 24-26.

[3]Zhang Shuzhong. , The Status, Problems and Countermeasures of Library Electronic Journal Navigation system[J] . Modern intelligence,2008,(4):51-53.

[4]Liu Zheng. The Present Situation and Development of Digital Resource Integration [J]. Books intelligence knowledge, 2003, (5): 40-41. 
[5] Dong Li.Research and Implementations of E-Resources Navigating Systems [J]. Modern library and information technology,2004,(9):50-53.

[6] Li Zhong. Development Analysis of Electronic Resource Guide System in University Library [J]. Modern intelligence, 2010,(6): 128-129.

[7] Zeng Jialin. Discussion on the Construction of Library Periodical Resources Navigation System [J]. Journal of Medical Informatics, 2006,(6): 454-455.

[8] Fang Wen. How to Build a Navigation System of Digital Resources[J]. Shanxi Library Journal, 2004,(4): 29-32.

[9] Song Ailin. Design of Library Digital Resource Compound Category Navigation System[J]. Journal of Xichang College·Natural Science Edition,2014,(3):70-72

[10]Yu Bing.On Information Navigation System Construction of the Key Disciplines and Inspiration[J].Journal of Henan University of Technology(Social Science),2010,(9):131-133.

[11] Bai Yongge, The Design and Practice of an Integrated E-Resource System for Aggregation Service[J]. Journal of University Library,2005,(1)34-37.

[12]Gao Xiaohua, The Study of Practical Techniques of Digital Resources Integration in Library[J].Journal of Xi'an University of Arts and Science(Social Sciences Edition),2001,(5),127129. 